\title{
Cyclical Vomiting
}

National Cancer Institute

\section{Source}

National Cancer Institute. Cyclical Vomiting. NCI Thesaurus. Code C117014.

A condition characterized by recurrent, self-limiting episodes of vomiting associated with intense nausea, pallor, and lethargy. It is commonly a migraine precursor. 